\title{
Isolation of developmentally regulated genes from the edible mushroom Agaricus bisporus
}

\author{
Piet W. J. De Groot, ${ }^{1,2}$ Peter J. Schaap, ${ }^{1}$ Leo J. L. D. Van Griensven ${ }^{2}$ \\ and Jaap Visser ${ }^{1}$
}

Author for correspondence: Jaap Visser. Tel: +31317484439. Fax: +31317484011 .
e-mail : office@algemeen.mgim.wau.nl

1 Section Molecular Genetics of Industrial

Microorganisms,

Wageningen Agricultural

University, Dreijenlaan 2,

NL-6703 HA, Wageningen,

The Netherlands

2 Mushroom Experimental

Station, PO Box 6042,

NL-5960 AA, Horst,

The Netherlands

\begin{abstract}
From a CDNA library, constructed from mushroom primordia, nine CDNAs were isolated which were either induced or specifically expressed during fruit body development and maturation of the basidiomycete Agaricus bisporus. These CDNAs varied in size from 372 to 1019 bp and hybridized to transcripts of 400-1600 nt. Four of the CDNAs were only expressed in the generative phase of the life cycle while the other five cDNAs were strongly induced but had low steady-state mRNA levels in vegetatively grown mycelium of the hybrid strain Horst U1. An apparent full-length cDNA could be identified by sequence analysis and specified a putative protein homologous to the $\delta$-subunit of the mitochondrial ATP synthase complex of Saccharomyces cerevisiae and Neurospora crassa. For one of the partial CDNAs, significant homology was found with a family of cell division control proteins, while another partial CDNA appeared to encode a cytochrome P450. All CDNAs, except the presumed cytochrome-P450-specifying CDNA (cypA), hybridized with single copy genes scattered over the Agaricus genome. For the cypA gene, the presence of several additional copies was shown by heterologous hybridizations. Based on changes in expression levels of the fruit-body-induced genes during development coinciding with alterations in morphological appearance of mushrooms, four stages of development were distinguished during growth and maturation of $A$. bisporus fruit bodies.
\end{abstract}

Keywords: Agaricus bisporus, fruit body development, ATP synthase $\delta$-subunit, septin, cytochrome P450

\section{INTRODUCTION}

The basidiomycete Agaricus bisporus is cultivated all over the world in large quantities for human consumption. During the cultivation process, fruit bodies appear in flushes on a casing layer covering compost precultured with vegetatively growing Agaricus mycelium. After colonization of the casing layer, fruit body formation is initiated by changing the temperature and carbon dioxide concentration of the environment.

In the past, fruit body development of A. bisporus has been studied by measuring activities of a number of enzymes involved in carbon metabolism. Mannitol dehydrogenase and glucose-6-phosphate dehydrogenase

Abbreviation: $\mathrm{CHEF}$, contour-clamped homogeneous electric field.

The EMBL accession numbers for the sequences of the putative atp $D$, sepA and cypA CDNAs reported in this paper are Z82019, Z82020 and Z82021. were found to have highest activities at the onset of fruit body formation of the successive flushes (Hammond \& Nichols, 1976; Hammond, 1981), while trehalase and glycogen phosphorylase peak at mid-flush (Wells et al., 1987). Although this knowledge led to a better understanding of some aspects of carbon metabolism during fruit body formation, the molecular biology underlying fruit body initiation and maturation remained unclear. In order to study the genetics of Agaricus fruit body formation, we have started with the isolation and characterization of a number of genes that are specifically expressed during this process of morphogenesis. For the isolation of developmentally expressed genes, two methods are usually applied. Differential screening techniques have been used successfully to isolate developmentally regulated genes from the basidiomycetes Coprinus cinereus (Yashar \& Pukkila, 1985), Schizophyllum commune (Mulder \& Wessels, 1986) and Agrocybe aegerita (Salvado \& Labarère, 
1991). No sequence information or data concerning the function of the deduced proteins of these genes is available except for the $S c 1-S c 4$ genes of $S c h$. commune (Schuren \& Wessels, 1990), which belong to a fungal gene family encoding small hydrophobic cell wall proteins. Recently, using a similar differential screening method, we have cloned a hydrophobin-encoding gene (bypA) from A. bisporus (De Groot et al., 1996). This gene was one of only two individual cDNAs of developmentally expressed genes that were isolated by this approach. The high expression levels of these genes, accumulating to approximately $6 \%(b y p A)$ and $4 \%$ (pDG47) of the total mRNA pool in pin-stage mushrooms, frustrated detection of other developmentally regulated genes.

Alternatively, when considerable sequence information of differentially expressed genes from related organisms is known, approaches using heterologous hybridization or PCR techniques can be used to isolate differentially expressed genes, as was demonstrated for the ascomycete Aspergillus fumigatus (Thau et al., 1994) and the basidiomycete Lentinus edodes (Kajiwara et al., 1992). However, as was shown by the direct cloning of the ras genes of the basidiomycetes L. edodes (Hori et al., 1991) and C. cinereus (Ishibashi \& Shishido, 1993), genes that are not differentially expressed were also cloned in this way, illustrating differences in gene regulation during development of apparently closely related organisms.

For further study of the genetics of fruit body formation, we wanted to investigate the structure, function and expression of more genes involved in fruit body formation. Due to the unusually high expression levels of the two previously cloned genes we deduced that repetition of conventional differential screening methods would result in only those cDNAs already cloned. Therefore cDNA clones, present in a cDNA library constructed from small developing mushrooms, were individually screened for elevated mRNA levels in the generative phase of the life cycle. In this way, nine new cDNAs corresponding to unlinked genes were isolated which are strongly induced during the generative phase of the life cycle. Three of those cDNAs could be identified by sequence analysis combined with a database search.

\section{METHODS}

Strains and culture conditions and recombinant DNA techniques. Agaricus bisporus strain Horst U1 and its homokaryotic constituents H39 and H97 were grown as mycelial mats in DT80 medium (Sonnenberg et al., 1988) supplemented with $3 \%(w / v)$ glucose. After $14 \mathrm{~d}$ growth at $24{ }^{\circ} \mathrm{C}$, the mycelium was harvested by filtration over nylon gauze, immediately frozen in liquid nitrogen, and stored at $-70^{\circ} \mathrm{C}$. Horst U1 was also grown on Cellophane sheets in Petri dishes containing sterilized commercially available compost solidified with $1.5 \%(\mathrm{w} / \mathrm{v})$ agar. Colonies were collected after $10 \mathrm{~d}$ growth at $24^{\circ} \mathrm{C}$ and frozen in liquid nitrogen.

A. bisporus Horst $\mathrm{U} 1$ fruit bodies were obtained using a 10 or $12 \mathrm{~d}$ flushing cycle (Van Gils, 1988). Primordia and mushrooms were harvested from the first appearance of fruit bodies (5-6 d after fruit body initiation) to harvest stage (10-12 d after fruit body initiation). After immediate freezing in liquid nitrogen, fruit bodies were stored at $-70{ }^{\circ} \mathrm{C}$.

Standard DNA manipulations were carried out essentially as described in Sambrook et al. (1989). Restriction enzymes and other enzymes used for DNA manipulations were purchased from BRL and used according to the supplier's instructions. Escherichia coli SolR cells (Stratagene) were used for in vivo excision of cloned cDNA inserts. The cDNA clones were sequenced by the method of Sanger et al. (1977) using a Thermo Sequenase fluorescent-labelled primer cycle sequencing kit with 7-deaza-dGTP (Amersham) and an ALF automated sequencer (Pharmacia).

Total RNA isolation and Northern analysis. Total RNA for Northern analyses was isolated from fruit bodies and mycelium using TRIzol reagent (BRL). The concentration of the RNA samples was determined spectrophotometrically. Equal amounts of RNA were denatured in $10 \times$ SSC (SSC is $0 \cdot 15 \mathrm{M}$ $\mathrm{NaCl}, 0.015 \mathrm{M}$ trisodium citrate, $\mathrm{pH} 7 \cdot 0$ ) and $6.15 \mathrm{M}$ formaldehyde and spotted on Hybond- $\mathrm{N}$ membrane (Amersham), or denatured using glyoxal and dimethyl sulfoxide by standard techniques, separated on a $1.6 \%(\mathrm{w} / \mathrm{v})$ agarose gel and transferred to Hybond-N membrane. mRNA lengths were determined by co-electrophoresis of RNA molecular mass markers (BRL) that were stained separately with methylene blue after transfer of the RNA to Hybond-N membranes (Sambrook et al., 1989). Hybridization of RNA blots was executed at $42{ }^{\circ} \mathrm{C}$ in standard hybridization buffer (SHB is $6 \times$ SSC, $5 \times$ Denhardt's solution, $0.5 \%$ SDS and $100 \mu \mathrm{g}$ denatured herring sperm DNA ml ${ }^{-1}$ ) to which $10 \%$ $(\mathrm{w} / \mathrm{v})$ dextran sulphate and $50 \%(\mathrm{v} / \mathrm{v})$ formamide was added. Washing was performed at $65^{\circ} \mathrm{C}$ to a final stringency of $0.1 \times$ SSC, $0.1 \%$ SDS. As a loading control, Northern blots were probed with an A. bisporus $28 \mathrm{~S}$ rDNA fragment (Schaap et al., 1996). Signal intensities were compared by scanning the autoradiograms with an Ultroscan XL laser densitometer (LKB).

Selection of fruit-body-induced CDNAs. For the detection of fruit-body-induced clones present in a primordial cDNA expression library (De Groot et al., 1996), total RNA was isolated from mushrooms grown under the same conditions (12 d flushing cycle) used to construct this cDNA library. Northern slot blots were prepared containing RNA of stage 1 (pin stage) mushrooms ( 5 and $0.05 \mu \mathrm{g}$ ), mature spore-bearing mushrooms $(5 \mu \mathrm{g})$ and mycelium vegetatively grown on glucose $(5$ and $0.05 \mu \mathrm{g})$. The blots were hybridized with 100 individual cDNA clones obtained by random excision of part of the cDNA library. The complete inserts of the clones were individually amplified using PCR and pBluescript-specific primers $5^{\prime}$ and $3^{\prime}$ adjacent to the insert sequences. The products obtained were labelled with $\left[\alpha-{ }^{32} \mathrm{P}\right] \mathrm{dATP}$ by random priming (Feinberg \& Vogelstein, 1983).

Clones which showed a 100 -fold or more increase in signal strength in fruit body RNA compared to glucose-grown mycelium RNA were rehybridized to Northern blots containing size-fractionated RNA isolated from mature fruit bodies and vegetative mycelium grown on sterilized compost, to confirm induction of the corresponding genes in the fruit bodies and to determine the length of the corresponding mRNA.

Isolation of total genomic DNA and chromosome assignment. Total DNA from strains H39 and H97 was isolated according to the method of De Graaff et al. (1988), digested with various restriction enzymes, separated on $0.8 \%$ agarose gels and transferred onto Hybond-N membranes. Contour-clamped 
homogeneous electric field (CHEF) electrophoresis of intact chromosomal DNA of $\mathrm{H} 39$ and $\mathrm{H} 97$ was performed as described by Sonnenberg et al. (1996) using a Bio-Rad CHEF DrIl system. The chromosomes were transferred by capillary blotting to a Hybond-N membrane. Membranes were hybridized overnight in $\mathrm{SHB}$ at $65^{\circ} \mathrm{C}$ and stringently washed $\left(0.1 \times\right.$ SSC, $0.1 \%$ SDS at $\left.65^{\circ} \mathrm{C}\right)$. Heterologous hybridizations were performed at $56^{\circ} \mathrm{C}$ with a final washing in $1 \times \mathrm{SSC}$, $0 \cdot 1 \%$ SDS at $56^{\circ} \mathrm{C}$. The amplified inserts of the cDNA clones were used as probes. For clones that could not be assigned to a single chromosome of one of the homokaryotic constituents of Horst U1 using CHEF gel electrophoresis followed by Southern analysis, definite assignment was achieved by linkage analysis. Segregation of these clones and previously cloned marker genes was studied in a set of 87 homokaryotic offspring (Sonnenberg et al., 1996).

Nucleotide and protein sequence comparisons. Database searches and other sequence manipulations were performed with the University of Wisconsin Genetics Computer Group (GCG) sequence analysis software package. Homology values were calculated from optimal alignments between two sequences using the GCG program BESTFIT (Devereux et al., 1984).

\section{RESULTS}

\section{Isolation of fruit-body-linked genes}

In a previous study, differential screening techniques led to the isolation of two $A$. bisporus genes that are specifically expressed in fruit bodies. The isolation of these genes, bypA and pDG47, was based on their abundant presence in a pin-stage cDNA expression library (De Groot et al., 1996). In order to isolate more developmental genes whose transcriptional activities are induced during fruit body formation, we individually screened 100 cDNA clones, provisionally designated pDG101-200, from the same library for elevated mRNA levels during fruit body formation. For this, we compared the steady-state transcript levels of each clone in primordia, in spore-bearing mature mushrooms and in vegetative mycelium grown on glucose by Northern slot blot analysis. One cDNA clone showed reduced expression levels in fruit bodies compared to mycelium, 41 cDNA clones did not show significant differences in RNA expression levels between fruit bodies and mycelium, while $33 \mathrm{cDNA}$ clones showed expression levels elevated up to a 100-fold in fruit bodies compared to mycelium. Twenty-five cDNA clones showed a 100-fold or more induction in the generative phase of the life cycle and these were further analysed. These 25 clones were screened by Southern analysis (not shown) for the occurrence of the two previously isolated fruit-bodyspecific genes. Consistent with the high expression levels of those genes, nine clones hybridized with bypA and six with pDG47.

\section{Identification of atpD, sepA and cypA}

The 10 newly isolated cDNA clones were then subjected to sequence analysis. Two clones, pDG122 and pDG195, both specifying a gene(s) with negligible expression levels in glucose-grown mycelium, were found to contain parts of the same gene. Clone pDG195 contained an insert of $433 \mathrm{bp}$ ending with a poly(A) tail and this sequence appeared to be identical to the first $433 \mathrm{bp}$ of clone pDG122. In the latter clone, this sequence was followed by an additional insert sequence of $800 \mathrm{bp}$.

Table 1. Characteristics of developmentally regulated genes of $A$. bisporus

\begin{tabular}{|c|c|c|c|c|c|}
\hline Clone & $\begin{array}{c}\text { Size of } \\
\text { cDNA (bp) }\end{array}$ & $\begin{array}{c}\text { Size of } \\
\text { mRNA (nt) }\end{array}$ & $\begin{array}{c}\text { mRNA level } \\
\text { in veg. grown } \\
\text { mycelium* }\end{array}$ & Chromosome $\dagger$ & $\begin{array}{l}\text { Putative gene } \\
\text { product }\end{array}$ \\
\hline byp $A$ & 535 & 550 & - & III & $\begin{array}{l}\text { Cell-wall- } \\
\text { associated } \\
\text { hydrophobic } \\
\text { protein }\end{array}$ \\
\hline pDG47 & 481 & 500 & - & XII & Unknown \\
\hline pDG144 & 783 & 900 & - & VII & Unknown \\
\hline pDG174 & 532 & 1050 & - & VII & Unknown \\
\hline pDG175 & 372 & 400 & - & VIII & Unknown \\
\hline pDG195 & 433 & 550 & - & VI & Unknown \\
\hline pDG102 & 718 & 1600 & + & II & Septin \\
\hline pDG125 & 932 & 1600 & + & $\mathrm{XI}$ & Cytochrome P450 \\
\hline pDG172 & 1019 & 1350,1500 & + & III & Unknown \\
\hline pDG183 & 648 & 650 & + & II & $\begin{array}{l}\text { ATP synthase } \\
\text { complex } \delta \text {-subunit }\end{array}$ \\
\hline pDG192 & 717 & 850 & + & V & Unknown \\
\hline
\end{tabular}

* -, mRNA level below detection limit; + , low mRNA level detected in vegetatively grown mycelium. † Chromosomal localizations were done by CHEF gel electrophoresis followed by Southern analysis. cDNAs hybridizing to chromosomes III or IV were re-analysed by linkage analysis. 

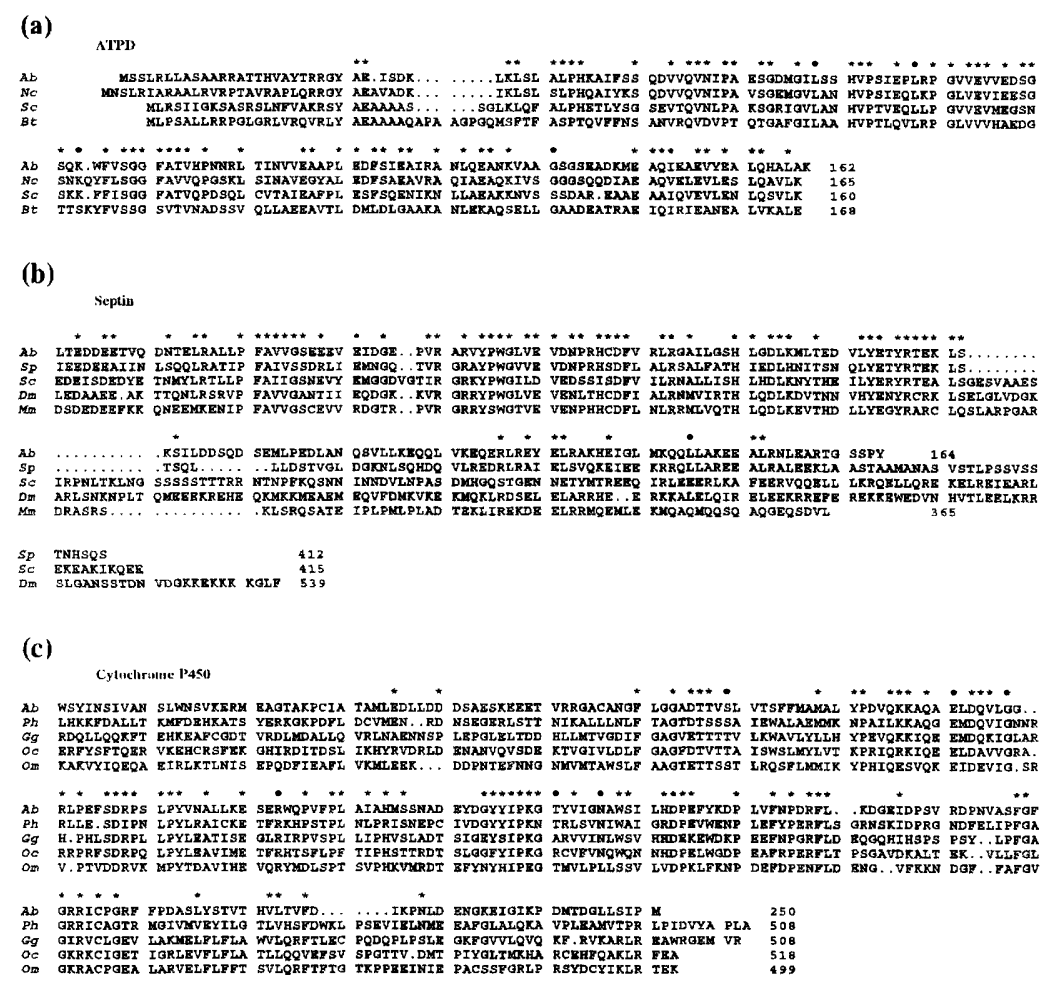

Fig. 1. Alignment of the putative translation products of three fruit-body-induced clones, pDG102, pDG125 and pDG183, with putative homologous proteins. Residues which are identical to $A$. bisporus in at least two of the related proteins are marked by asterisks above the sequences. (a) Predicted amino acid sequence of ATPD translated from clone pDG183. The $A$. bisporus (Ab) ATPD protein was aligned with ATP synthase $\delta$-subunits from N. crassa (Nc; Kruse \& Sebald, 1984), Sac. cerevisiae (SC; Giraud \& Velours, 1994) and Bos taurus (bovine) (Bt; Runswick et al., 1990). (b) Predicted amino acid sequence of SEPA translated from clone PDG102. The partial $A$. bisporus (Ab) SEPA was aligned with Schizosaccharomyces pombe Spn3p (Sp; GenBank accession no. U29889), Sac. cerevisiae Cdc11p (Sc; GenBank accession no. L16550), Drosophila melanogaster PNUT (Dm; Neufeld \& Rubin, 1994) and Mus musculus (murine) DIFF6 ( $\mathrm{Mm}$; Nottenburg et al., 1990). (c) Predicted amino acid sequence of CYPA translated from clone pDG125. The partial $A$. bisporus ( $A b$ ) CYPA was aligned with Petunia hybrida CYP75A3 (Ph; Holton et al., 1993), Gallus gallus (chicken) CYP17 ( $\mathrm{Gg}$; Ono et al., 1988), Oryctolagus cuniculus (rabbit) CYP1A1 (Oc; Kagawa et al., 1987) and Onchorychus mykiss (rainbow trout) CYP2M1 (Om: GenBank accession no. U16657).
Since Northern analysis of size-fractionated RNA showed that clone pDG195 hybridized to a single transcript of only $550 \mathrm{nt}$ (Table 1), pDG122 is most probably the result of a combination of two unrelated cDNAs. Therefore, of these two clones, only pDG195 was used for further study.

Of the remaining nine clones, only clones pDG175 and pDG183 appeared to be full length (Table 1). A database search of clone pDG183, with an insert of $648 \mathrm{bp}$, identified this cDNA as encoding the $\delta$-subunit of the mitochondrial ATP synthase complex (ATPD). The deduced A. bisporus ATPD amino acid sequence was found to have $63 \%, 51 \%$ and $36 \%$ identity with ATP synthase $\delta$-subunits of the ascomycete Neurospora crassa, the yeast Saccharomyces cerevisiae and Bos taurus (bovine), respectively (Fig. 1a). From the primary translation products of the Sac. cerevisiae and the bovine genes, a 22 amino acid mitochondrial targeting peptide is cleaved off and also for $N$. crassa ATP synthase $\delta$ subunit a mitochondrial targeting peptide was predicted. The A. bisporus at $D$ open reading frame encodes a putative protein of 162 amino acids that contains the conserved RXY $\downarrow(S / A)$ motif for cleavage of mitochondrial targeting peptides (Gavel \& von Heijne, 1990) and therefore a mitochondrial targeting sequence of 25 amino acids, rich in basic (arginine) and polar (serine) residues, is suggested.

For two partial cDNAs, pDG102 and pDG125, significant homology with database sequences was also found. The proposed translation of the largest open reading frame of clone $\mathrm{pDG} 102$, with an insert of $718 \mathrm{bp}$, showed $46 \%$ identity with the carboxy-terminal half of Schizosaccharomyces pombe Spn3p, $42 \%$ identity with Sac. cerevisiae Cdc11p, $40 \%$ identity with the Drosophila PNUT protein and 39\% identity with murine DIFF6 (Fig. 1b). These proteins are mitotic cell division control proteins belonging to the septin family, and might be involved in cytokinesis. Clone pDG102, now renamed $\operatorname{sep} A$, hybridized with a transcript of $1600 \mathrm{nt}$ (Table 1) which could encode a protein of about $400-500$ amino acids, a size which is in accordance with the size of the four septin proteins to which SEPA was aligned.

Clone pDG125 has an insert of 932 bp ending in a poly (A) tail. On the positive strand, a large open reading frame of $750 \mathrm{bp}$ was found of which the deduced amino acid sequence showed significant homology with the carboxy-terminal half of cytochrome P450 proteins which are currently classified into 74 families (Nelson et al., 1996). Highest homology was found with two flavonoid 3',5' hydroxylases, CYP75A1 and CYP75A3, of Petunia bybrida, proteins that belong to cytochrome P450 family 75 . The partial A. bisporus amino acid sequence showed $36 \%$ identity with these proteins. The homology found with members of other cytochrome P450 subfamilies was $32 \%$ with chicken CYP17, $31 \%$ with rabbit CYP1A1 and $28 \%$ with trout CYP2M1 (Fig. 1c). Northern analysis showed that pDG125 hybridized to a transcript of $1600 \mathrm{nt}$ (Table 1) that could encode a 

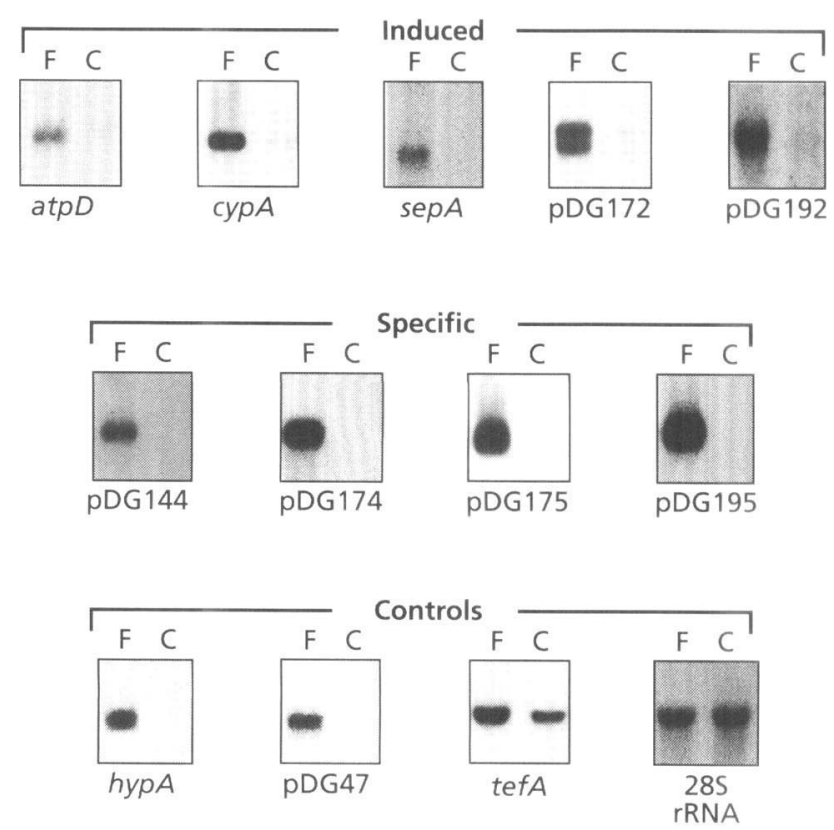

Fig. 2. Transcript levels of CDNA clones in fruit bodies $(F)$ and compost-grown mycelium (C). The inserts of all deduced fruitbody-specific and fruit-body-induced CDNA clones were individually used as probes. Control hybridizations were performed with hypA, pDG47 (De Groot et al., 1996), tefA (Schaap et al., 1997) and a 285 rDNA probe (Schaap et al., 1996). Sizes of the mRNAs of all fruit-body-specific or fruitbody-induced genes are listed in Table 1.

protein of about 500 amino acids and this is in accordance with the size of cytochrome $\mathrm{P} 450$ proteins. Therefore, pDG125 was tentatively renamed cypA.

\section{Classification into fruit-body-specific and fruit-body- induced genes}

Besides determination of transcript size, the Northern analyses of size-separated RNA were also used to reestablish the induction of expression of the nine clones in fruit bodies by comparing expression in mature fruit bodies with expression in mycelium grown on sterilized compost. The previously isolated fruit-body-specific bypA gene and clone pDG47, the constitutively expressed tef A gene (Sonnenberg et al., 1996) and 28S rDNA (Schaap et al., 1996) were used as controls. Four of the newly isolated cDNAs and the controls bypA and pDG47 showed strong signals upon hybridization with fruit body RNA while their mRNA levels in RNA from mycelium grown on compost were the same as those obtained with glucose-grown mycelium, below the detection limit (Fig. 2), even after prolonged exposure (not shown). These cDNAs were therefore considered as being obtained from genes that are only expressed in the generative phase of the life cycle and were classified as fruit-body-specific genes. For the other cDNAs, weak hybridization signals were observed with RNA from compost mycelium as was also observed with RNA from glucose-grown mycelium in the initial screening, but they showed a strong increase in signal strength upon hybridization with RNA obtained from fruit bodies (Fig. 2). These clones are further denoted as being obtained from fruit-body-induced genes. The tef $A$ control showed comparable levels of expression in compost mycelium and fruit bodies. All cDNA clones, except pDG172, hybridized to transcripts of one apparent size. For pDG172, two transcripts with a small size difference are visible (Fig. 2). The results from the Northern analyses are summarized in Table 1 . The previously isolated genes bypA and pDG47 are added to the Table for comparison.

\section{The fruit-body-specific and fruit-body-induced genes are scattered over the genome}

The genomic organization of the fruit-body-linked cDNAs was studied using genomic DNA of the homokaryotic constituents of Horst U1. Southern analyses of digested DNA fragments showed that all clones, except cypA, probably represent single copy genes. For cypA, several strong and weak hybridizing bands were observed using heterologous hybridization conditions and this indicates that there are additional copies of the cytochrome-P450-encoding cyp gene family in the Agaricus genome (results not shown).

The chromosomal localization of all clones was analysed using CHEF electrophoresis of total DNA from the parental strains $\mathrm{H} 39$ and $\mathrm{H} 97$ followed by Southern analysis. All clones, except cypA, hybridized to single chromosome bands representing homologous chromosomes of the two karyotypes (Sonnenberg et al., 1996) and the corresponding genes are divergently located on the Agaricus genome (Fig. 3 and Table 1). For cypA, using heterologous hybridization conditions, a strong hybridization signal was observed for chromosome XI, while additional weaker signals were found for at least chromosomes VII, VIII and XIII and the unseparated chromosomes III/IV (Fig. 3). This is consistent with the multiple signals found by Southern analysis of digested total DNA. It therefore appears that other cytochromeP450-encoding genes are located on different chromosomes in the Agaricus genome.

The bypA gene (De Groot et al., 1996) and pDG172 were localized with CHEF analysis on either chromosome III or IV (Fig. 3) and had to be assigned by linkage analysis. Using homokaryotic offspring, 100\% linkage was found for both genes with two markers, the $p g k A$ gene (Sonnenberg et al., 1996) and anonymous marker p33N5 (Kerrigan et al., 1993), both residing on chromosome III. No linkage was found with the marker genes $r p a B$ and pruA, both localized on chromosome IV (Sonnenberg et al., 1996). Consequently, bypA and the gene corresponding to pDG172 are localized on chromosome III of both parental strains. None of the clones that are localized on the same chromosomes cross-hybridized or shared significant sequence homology. All these clones hybridized with transcripts of different size and taken together this indicates that all cDNAs represent genes of different loci of the A. bisporus genome. 

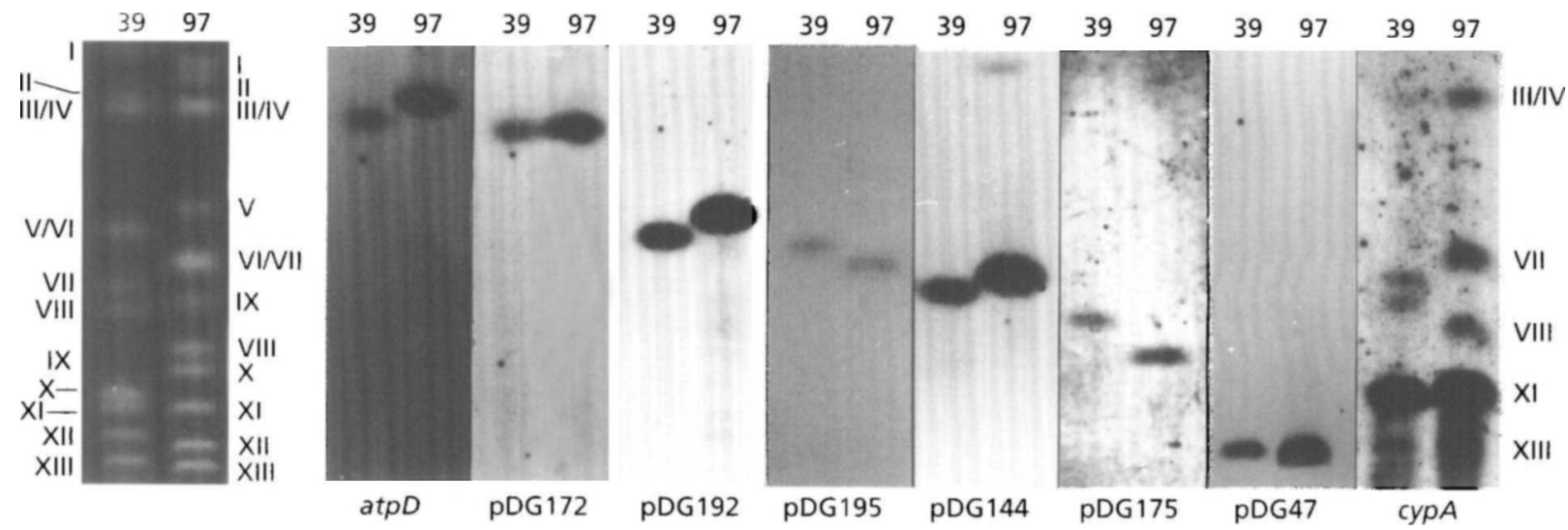

Fig. 3. CHEF analysis of $A$. bisporus strains $\mathrm{H} 39$ and H97. Chromosomes of the parental lines of Horst U1 separated by CHEF gel electrophoresis after staining with $\mathrm{EtBr}$ (left panel) and after hybridization with the different fruit-body-specific and fruit-body-induced clones. For all chromosomes to which fruit-body-specific or fruit-body-induced genes were assigned, one representative hybridization is shown. For $c y p A$, a heterologous hybridization showing the presence of additional cypA copies is presented. Chromosomes are indicated by Roman numerals according to Sonnenberg et al. (1996).

(a)

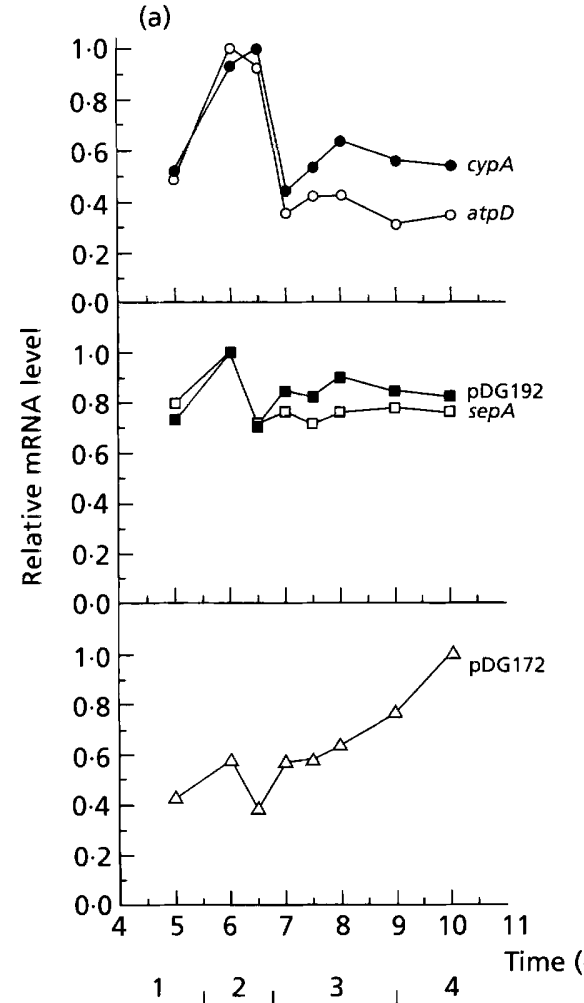

(b)

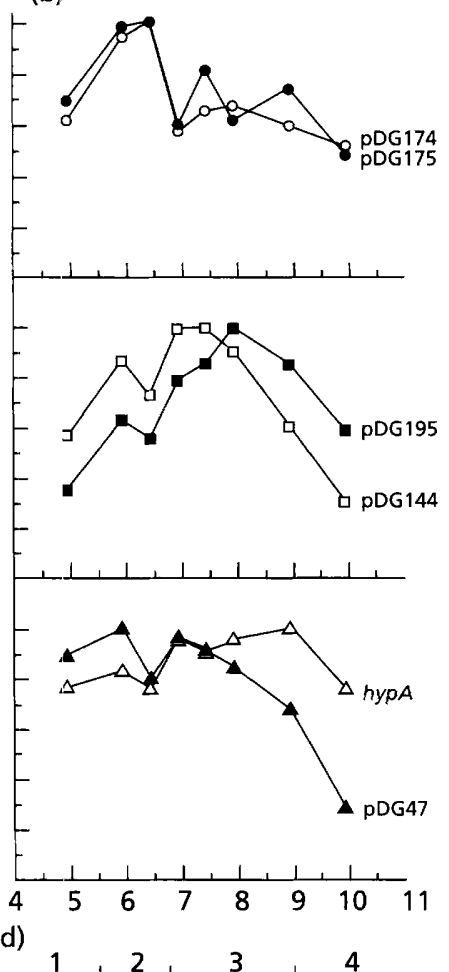

Developmental stage

Fig. 4. Relative mRNA levels of the fruitbody-induced (a) and fruit-body-specific (b) genes in mushrooms harvested at day 5 to day 10 during fruit body development. Samples were taken daily at 9 a.m. and at days 6 and 7 additional samples (6.5 and 7.5) were isolated at 9 p.m. The inserts of the fruit-body-induced and fruit-body-specific cDNA clones and of hypA and pDG47 were used as probes. Transcript levels were normalized against 28S rRNA and for each gene the highest level recorded was arbitrarily set to $1 \cdot 0$.

\section{Developmental expression of the fruit-body-specific and fruit-body-induced genes}

The mRNA levels of all the newly isolated fruit-bodylinked cDNAs, the previously identified $h y p A$ gene and pDG47 were followed during development and maturation of Horst U1 fruit bodies during a first flush using Northern slot blot analysis. For this, fruit bodies were grown in a $10 \mathrm{~d}$ flushing cycle using commercial cultivation conditions. Transcript levels were followed from the first visual appearance of primordia $5 \mathrm{~d}$ after initiation of fruit body formation until spore-bearing gills were exposed and the veil broke. Several types of expression patterns were observed (Fig. 4). Two fruitbody-induced genes (atpD and cypA) and two fruitbody-specific genes (pDG174 and pDG175) have highest 
mRNA levels $6 \mathrm{~d}$ after fruit body initiation. Two other fruit-body-specific genes, pDG144 and pDG195, show highest transcript levels from day 7 to day 9, whereas their mRNA levels in mature mushrooms (day 10) are clearly decreased. Fruit-body-specific gene pDG47 also showed its lowest expression levels in these mature mushrooms. Two fruit-body-induced genes, pDG192 and $\operatorname{sep} A$, and the bypA gene appeared to have a more or less constant expression level during these $6 \mathrm{~d}$ of mushroom development. Finally, the fruit-body-induced gene pDG172 was unique in showing its highest level of expression in mature fruit bodies.

\section{DISCUSSION}

Differential screening techniques have been successfully applied for the cloning of developmentally regulated genes from several fungi, including a few basidiomycetes. However, with this approach we succeeded in isolating only two fruit-body-specific genes (De Groot et al., 1996). In our new strategy, we individually screened 100 cDNA clones from a fruit body cDNA library for elevated expression of the corresponding genes in fruit bodies. Although only a small part of the cDNA population in the cDNA library was examined, nine new differentially regulated cDNAs were isolated originating from genes that are induced coordinately with fruit body formation. Northern analyses showed that most of the cDNA clones isolated in this study are, although not detected by the previous differential screening, highly expressed in A. bisporus fruit bodies. This is underlined by the results from hybridization of pDG144 to the cDNA library. This clone hybridized with approximately $1 \%$ of the clones of this library and this emphasizes the unusually strong expression of the two fruit-body-specific clones that were found by differential screening.

Sterile compost supports good growth in the vegetative phase of the life cycle. Under normal cultivation conditions, other micro-organisms present in the compost and necessary for normal fruit body induction somehow accelerate the rate of colonization of the compost by $A$. bisporus but these micro-organisms appear to have no effect on the total mycelial biomass formed (Smith et al., 1995). Nevertheless, we tried to avoid false positives that have variations in expression levels as a consequence of metabolic differences resulting from the different growth conditions used by selecting clones of which the corresponding mRNA level in primordia and/or mature mushrooms was elevated at least a 100-fold compared to the level in mycelium. Furthermore, all selected fruit-body-induced clones showed similar expression levels in mycelium grown on compost and glucose and this excludes any carbon source effects in our screening results. However, we cannot exclude that a part of the difference in expression levels observed for the fruit-body-induced clones is due to metabolic differences as a result of different growth conditions.
The cDNA library used in this study was composed of poly(A) RNA isolated from a mixture of primordia and small mushrooms which were picked on the same day, and is thus enriched in CDNAs from genes that show high mRNA levels late in the development of primordia and their transition into mature mushrooms. In order to isolate genes that are active at earlier stages of fruit body development, fertile mycelium that is starting to form mycelial aggregates, a process occurring prior to primordium formation, would be a better source of material for constructing such a cDNA library. In the basidiomycetes Sch. commune and Agr. aegerita, culturing under axenic conditions leads to normal fruit body formation and this enables the isolation of mycelium that undergoes developmental changes. $A$. bisporus, on the other hand, is very reluctant to fruit under axenic conditions and under those conditions mycelial aggregates have only been observed in a mutant; however, this mutant shows no sign of further differentiation or maturation. The mutant is also unable to produce normal fruit bodies on compost (Hammond \& Burton, 1996). Normal A. bisporus fruit body development requires the presence of a particular kind of microflora in the compost during cultivation (Miller et al., 1995). The isolation of genes involved in the initial steps of fruit body formation of $A$. bisporus may therefore require the isolation of RNA from aggregated mycelium from non-sterile compost shortly after fruiting is initiated.

Based on changes in morphological appearance that can be visualized by light microscopy (De Groot et al., 1996), we can divide $A$. bisporus mushroom development into four stages. These stages differ from the arbitrary stages previously defined by Hammond \& Nichols (1975). The transition from pin-shaped (stage 1) mushrooms into stage 2 mushrooms is accompanied by a transient increase of expression of four genes at day 6. At this time-point, previously described as belonging to stage 1 , cap tissue becomes visible as a more dense type of mycelium. One day later, non-spore-bearing gills are already visible in cross-sections of these fruit bodies and the cap starts to enlarge rapidly (stage 3 ). During this stage, previously subdivided into stages 2 and 3, clones pDG144 and pDG195 have their highest levels of expression. Ten days after fruit body initiation, the now spore-bearing mushroom starts to unveil its gills and is considered mature (stage 4). This coincides with a decrease in expression of pDG47, pDG144 and pDG195 and increased expression of pDG172 (Fig. 4).

The three cDNA clones, $\operatorname{atpD}, \operatorname{sep} A$ and $c y p A$, for which significant homology with database sequences was found, all belong to the group of genes that are also expressed during the vegetative phase of the life cycle. Identification of genes specifically expressed during fruiting, however, seems to be more difficult and is hampered by the lack of morphological mutants and sequence information from genes involved in fruiting of other basidiomycetes. However, further studies on the regulation of the now cloned genes will lead to a better understanding of mushroom development. 


\section{ACKNOWLEDGEMENTS}

The authors thank Dr J. Baars and Mrs A. van de Munckhof of the Mushroom Experimental Station for performing the CHEF electrophoresis and for culturing the A. bisporus strains. We also thank Ms D. Basten and Mrs Y. Müller of MGIM for technical assistance.

\section{REFERENCES}

De Graaff, L. H., Van den Broek, H. \& Visser, J. (1988). Isolation and expression of the Aspergillus nidulans pyruvate kinase gene. Curr Genet 11, 499-503.

De Groot, P. W. J., Schaap, P. J., Sonnenberg, A. S. M., Visser, J. \& Van Griensven, L. J. L. D. (1996). The Agaricus bisporus bypA gene encodes a hydrophobin and specifically accumulates in peel tissue of mushroom caps during fruit body development. $J \mathrm{Mol}$ Biol 257, 1008-1018.

Devereux, J., Haeberli, P. \& Smithies, O. (1984). A comprehensive set of sequence analysis programs for the VAX. Nucleic Acids Res 12, 387-395.

Feinberg, A. P. \& Vogelstein, B. (1983). A technique for radiolabeling DNA restriction endonuclease fragments to high specific activity. Anal Biochem 132, 6-13.

Gavel, Y. \& von Heijne, G. (1990). Cleavage-site motifs in mitochondrial targeting peptides. Protein Eng 4, 33-37.

Giraud, M.-F. \& Velours, J. (1994). ATP-synthase of yeast mitochondria. Eur J Biochem 222, 851-859.

Hammond, J. B. W. (1981). Variations in enzyme activity during periodic fruiting of Agaricus bisporus. New Phytol 89, 419-428.

Hammond, J. B. W. \& Burton, K. S. (1996). Expression of intracellular enzymes during hyphal aggregate formation in a fruiting-impaired variant of Agaricus bisporus. Curr Microbiol 32, 252-255.

Hammond, J. B. W. \& Nichols, R. (1975). Changes in respiration and soluble carbohydrates during the post-harvest storage of mushrooms (Agaricus bisporus). J Sci Food Agric 26, 835-842.

Hammond, J. B. W. \& Nichols, R. (1976). Carbohydrate metabolism in Agaricus bisporus (Lange) Sing.: changes in soluble carbohydrates during growth of mycelium and sporophore. J Gen Microbiol 93, 309-320.

Holton, T. A., Brugliera, F., Lester, D. R., Tanaka, Y., Hyland, C. D., Menting, J. G. T., Lu, C.-Y., Farcy, E., Stevenson, T. W. \& Cornish, E. C. (1993). Cloning and expression of cytochrome P450 genes controlling flower colour. Nature 366, 276-279.

Hori, K., Kajiwara, S., Saito, T., Miyazawa, H., Katayose, Y. \& Shishido, K. (1991). Cloning, sequence analysis and transcriptional expression of a ras gene of the edible basidiomycete Lentinus edodes. Gene 105, 91-96.

Ishibashi, O. \& Shishido, K. (1993). Nucleotide sequence of a ras gene from the basidiomycete Coprinus cinereus. Gene 125, 233-234.

Kagawa, N., Mihara, K. \& Sato, R. (1987). Structural analysis of cloned cDNAs for polycyclic hydrocarbon-inducible forms of rabbit liver microsomal cytochrome $\mathrm{P}-450^{1}$. J Biochem 101, 1471-1479.

Kajiwara, S., Yamaoka, K., Hori, K., Miyazawa, H., Saito, T., Kanno, T. \& Shishido, K. (1992). Isolation and sequence of a developmentally regulated putative novel gene, priA, from the basidiomycete Lentinus edodes. Gene 114, 173-178.

Kerrigan, R. W., Royer, J. C., Baller, L. M., Kohli, Y., Horgen, P. A. \& Anderson, J. B. (1993). Meiotic behaviour and linkage relation- ships in the secondarily homothallic fungus Agaricus bisporus. Genetics 133, 225-236.

Kruse, B. \& Sebald, W. (1984). Nucleotide sequence of the cloned mRNA and gene of the delta subunit of the mitochondrial ATPsynthase from Neurospora crassa. In Abstracts of the Third European Bioenergetics Conference, September 2-7, vol. 3B, pp. 607-608. Hannover.

Miller, N., Gillespie, J. B. \& Doyle, O. P. E. (1995). The involvement of microbiological components of peat based on casing materials in fructification of Agaricus bisporus. In Science and Cultivation of Edible Fungi, pp. 313-321. Edited by T. J. Elliott. Rotterdam: Balkema.

Mulder, G. H. \& Wessels, J. G. H. (1986). Molecular cloning of RNAs differentially expressed in monokaryons and dikaryons of Schizophyllum commune in relation to fruiting. Exp Mycol 10, 214-227.

Nelson, D. R., Koymans, L., Kamataki, T., Stegeman, J. J., Feyereisen, R., Waxman, D. J., Waterman, M. R., Gotoh, O., Coon, M. J., Estabrook, R. W., Gunsalus, I. C. \& Nebert, D. W. (1996). P450 superfamily: update on new sequences, gene mapping, accession numbers and nomenclature. Pharmacogenetics 6, 1-42. Neufeld, T. P. \& Rubin, G. M. (1994). The Drosophila peanut gene is required for cytokinesis and encodes a protein similar to yeast putative bud neck filament proteins. Cell 77, 371-379.

Nottenburg, C., Gallatin, W. M. \& St John, T. (1990). Lymphocyte $\mathrm{HEV}$ adhesion variants differ in the expression of multiple gene sequences. Gene 95, 279-284.

Ono, H., Iwasaki, M., Sakamoto, N. \& Mizuno, S. (1988). cDNA cloning and sequence analysis of a chicken gene expressed during the gonadal development and homologous to mammalian cytochrome P-450c17. Gene 66, 77-85.

Runswick, M. J., Medd, S. M. \& Walker, J. E. (1990). The $\delta$-subunit of ATP synthase from bovine heart mitochondria. Biochem $J \mathbf{2 6 6}$, 421-426.

Salvado, J. C. \& Labarère, J. (1991). Isolation of transcripts preferentially expressed during fruit body primordia differentiation in the basidiomycete Agrocybe aegerita. Curr Genet 20, 205-210.

Sambrook, J., Fritsch, E. F. \& Maniatis, T. (1989). Molecular Cloning: a Laboratory Manual, 2nd edn. Cold Spring Harbor, NY: Cold Spring Harbor Laboratory.

Sanger, F., Nicklen, S. \& Coulson, A. R. (1977). DNA sequencing with chain-terminating inhibitors. Proc Natl Acad Sci USA 74, 5463-5467.

Schaap, P. J., Müller, Y., Baars, J. J. P., Op den Camp, H. J. M., Sonnenberg, A. S. M., Van Griensven, L. J. L. D. \& Visser, J. (1996). Nucleotide sequence and expression of the gene encoding $\mathrm{NADP}^{+}$-dependent glutamate dehydrogenase $(g d h \mathrm{~A})$ from Agaricus bisporus. Mol Gen Genet 250, 339-347.

Schaap, P. J., Müller, Y., Sonnenberg, A. S. M., Van Griensven, L. J. L. D. \& Visser, J. (1997). The Agaricus bisporus pruA gene encodes a cytosolic $\Delta^{1}$-pyrroline-5-carboxylate dehydrogenase which is expressed in fruit bodies but not in gill tissue. Appl Environ Microbiol 63, 57-62.

Schuren, F. H. J. \& Wessels, J. G. H. (1990). Two genes specifically expressed in fruiting dikaryons of Schizophyllum commune: homologies with a gene not regulated by mating-type genes. Gene 90, 199-205.

Smith, J. F., Wood, D. A. \& Thurston, C. F. (1995). Growth measurement of Agaricus mycelium in composted substrates as an indicator of compost selectivity and mushroom productivity. 
In Science and Cultivation of Edible Fungi, pp. 293-301. Edited by T. J. Elliott. Rotterdam: Balkema.

Sonnenberg, A. S. M., Wessels, J. G. H. \& Van Griensven, L. J. L. D. (1988). An efficient protoplasting/regeneration system for Agaricus bisporus and Agaricus bitorquis. Curr Microbiol 17, 285-291.

Sonnenberg, A. S. M., De Groot, P. W. J., Schaap, P. J., Baars, J. J. P., Visser, J. \& Van Griensven, L. J. L. D. (1996). The isolation of expressed sequence tags of Agaricus bisporus and their assignment to chromosomes. Appl Environ Microbiol 62, $4542-4547$.

Thau, N., Monod, M., Crestani, B., Rolland, C., Tronchin, G., Latgé, J.-P. \& Paris, S. (1994). rodletless mutants of Aspergillus fumigatus. Infect Immun 62, 4380-4388.
Van Gils, J. J. (1988). Cultivation. In The Cultivation of Mushrooms, pp. 263-308. Edited by L. J. L. D. Van Griensven. Rustington: Darlington Mushroom Laboratories.

Wells, T. K., Hammond, J. B. W. \& Dickerson, A. G. (1987). Variations in activities of glycogen phosphorylase and trehalase during the periodic fruiting of the edible mushroom Agaricus bisporus (Lange) Imbach. New Phytol 105, 273-280.

Yashar, B. M. \& Pukkila, P. (1985). Changes in polyadenylated RNA sequences associated with fruiting body morphogenesis in Coprinus cinereus. Trans Br Mycol Soc 84, 215-226.

Received 18 November 1996; revised 20 January 1997; accepted 6 February 1997. 